\title{
Petersen's hernia after gastric bypass for morbid obesity: a diagnostic challenge
}

\begin{abstract}
Petersen's hernia is an internal hernia caused by the herniation of intestinal loops through the defect created between the transverse mesocolon, the retroperitoneum and the afferent loop mesentery (Roux, Omega or others) after any type of gastrojejunostomy. With the growth of bariatric and metabolic surgery, particularly with the laparoscopic approach, there was an increase in this kind of complication with its associated morbidity and mortality. The diagnosis is challenging and can lead to treatment delay with devastating consequences. This review aims to describe the incidence of Petersen's hernia, its prevention strategies and to alert to the need of a high-index of suspicion on the diagnosis to a prompt treatment.
\end{abstract}

Keywords: obesity, gastric bypass, petersen's hernia
Volume 9 Issue 6 - 2019

\author{
Santos DC, ' Viveiros $\mathrm{O},{ }^{2}$ Gameiro $\mathrm{H},{ }^{\prime}$ \\ Pereira $J^{2}$ \\ 'Serviço de Cirurgia Geral, Unidade Local de Saúde do Litoral \\ Alentejano, Portugal \\ ${ }^{2}$ Serviço de Cirurgia Geral, Hospital Curry Cabral-Centro \\ Hospitalar Universitário Lisboa Central, Portugal
}

Correspondence: Daniel Costa Santos, Unidade Local de
Saúde do Litoral Alentejano, Monte do Gilbardinho, 7540-230
Santiago do Cacém, Portugal, Tel +35I91245747I; Email costasantos.danie@hotmail.com

Received: November II, 2019 | Published: December 20, 2019
Abbreviations: CT, computed tomography; OAGB, one anastomosis gastric bypass; RYGB, roux-en-y gastric bypass.

\section{Introduction}

Petersen's space (first described in 1900 by Dr. Walther Petersen) is a defect created after any gastrojejunostomy. Its limits are the transverse mesocolon, the retroperitoneum and the jejunal limb mesentery. The herniation of intestinal contents (mainly small bowel) through this defect it's called a Petersen's hernia.

\section{Discussion}

With the decrease in gastrojejunal anastomosis after antrectomy for peptic ulcer disease, the expansion of bariatric and metabolic surgery is leading to a new increase in the incidence of this disease, reported to be from $0,9 \%$ to $11.7 \%$. Kermansaravi et al., ${ }^{1}$ reported a reduced incidence when the defect is closed (11,7\% vs 2,5\%), but associated with prolonged operating time and further complications, like bleeding and hematoma formation. Some studies suggest it is also dependent on the surgeon's learning curve.

The probability of developing a Petersen's hernia is greater with a retrocolic alimentary loop $(4,5 \%)$ than with an antecolic one $(0,4 \%))^{2,3}$ The laparoscopic approach with its known advantages (less postoperative pain, shorter hospital stay and earlier resumption of normal activities), also leads to less adhesions formation and greater likelihood to develop internal hernias in long term. ${ }^{4}$ Although less frequent in one anasthomosis gastric bypass (OAGB) than in Rouxen-Y gastric bypass (RYGB), Facchiano et al., ${ }^{5}$ described the first case of Peterson's space hernia in this surgery, demonstrating that it does not eliminate the risk of developing internal hernias. Changing from retrocolic to antecolic bypass has been shown in multiple studies to reduce the incidence of internal hernias. ${ }^{6}$
Patients present with recurrent and intermittent abdominal pain, associated with nausea vomiting. These vague chronic symptoms should raise the suspicion of an internal hernia in patients submitted to bariatric and metabolic surgery, particularly with normal clinical and laboratory findings.

Abdominal CT scan with intravenous contrast should be considered in all patients with gastrojejunal anastomosis, as it is the most accurate diagnostic procedure. Common findings in CT scan are intestinal distention and herniation, mesenteric vessels rotation ("whirlpool" sign) and displacement of the Treitz ligament and distal ileum, with the herniated small bowel loop located above the gastric level. Ximenes $\mathrm{M}$ et al., ${ }^{7}$ also described the mesenteric vessel rotation together with mesenteric fat haziness to be the most sensitive signs for the diagnosis of internal hernias.

As internal hernias are particular diagnostic challenges, only suspected in symptomatic patients, this patient's benefit from observation by an experienced bariatric surgeon. ${ }^{8}$ Early diagnosis and treatment are mandatory to avoid major complications, such as incarceration and bowel ischaemia. ${ }^{9}$ Even with high index of suspicion, diagnostic laparoscopy may be necessary for the definite diagnosis.

Closure of the potential hernia sites do not prevent herniation in all patients due to massive loss of weight and abdominal fat after metabolic surgery, which can wider small mesenteric defects due to reduction of intraabdominal fat. ${ }^{2,10}$ Several techniques have been described for closure of the mesenteric defect., ${ }^{4,11}$ Paroz et al., ${ }^{4}$ reported a decrease in internal hernias incidence from $5,6 \%$ with separate stitches of absorbable suture, to $3,4 \%$ with separate stitches of non-absorbable suture, and finally to $1,3 \%$ with running stitches of non-absorbable suture, ${ }^{4}$ with further randomized studies needed to decide which is the best closure technique. 


\section{Conclusion}

Petersen's space hernias are rare complications after gastric bypass, with potentially fatal complications, such as bowel ischemia and perforation. Diagnosis is challenging, not only because of patient morphology, but also due to lack of clinical signs and professional experience with bariatric surgery. Laparoscopy is essential in diagnosis and treatment, not only in elective but also in emergency setting. ${ }^{12}$

\section{Acknowledgment}

None.

\section{Conflicts of interest}

The author declares that he has no conflicts of interest.

\section{Funding}

None.

\section{References}

1. Kermansaravi M, Kazazi M, Pazouki A. Petersen's space internal hernia after laparoscopic one anastomosis (mini) gastric bypass. Case Rep Surg. 2018;1:9576120.

2. de Bakker JK, Budde van Namen YW, Bruin SC, et al. Gastric bypass and abdominal pain: think of petersen hernia. J Soc Laparoendosc Surg. 2012;16(2):311-313.

3. Marcotte E, Chand B. Management and prevention of surgical and nutritional complications after bariatric surgery. Surg Clin North Am. 2016;96(4):843-856.
4. Paroz A, Calmes JM, Giusti V, et al. Internal hernia after laparoscopic roux-en-y gastric bypass for morbid obesity: a continuous challenge in bariatric surgery. Obes Surg. 2006;16(11):1482-1487.

5. Facchiano E, Iannelli A, Lucchese M. Internal hernia after mini-gastric bypass: myth or reality? J Visc Surg. 2016;153(3):231-232.

6. De La Cruz-Muñoz N, Cabrera JC, Cuesta M, et al. Closure of mesenteric defect can lead to decrease in internal hernias after roux-en-y gastric bypass. Surg Obes Relat Dis. 2011;7(2):176-180.

7. Ximenes MÁS, Baroni RH, Trindade R, et al. CT findings in Petersen's hernia as a complication of bariatric surgery with a Roux-en-Y gastric bypass. Einstein. 2008;6(4):452-458.

8. Magee C, Macadam R, Kerrigan DD. Petersen's hernia after laparoscopic roux-en-y gastric bypass-case report, diagnostic sign, and proposed classification system. Surg Obes Relat Dis. 2010;6(4):446-447.

9. Stenberg E, Szabo E, Ågren G, et al. Closure of mesenteric defects in laparoscopic gastric bypass: a multicentre, randomised, parallel, openlabel trial. Lancet. 2016;387(10026):1397-1404.

10. Faria G, Preto J, Oliveira M, et al. Petersen's space hernia: a rare but expanding diagnosis. Int J Surg Case Rep. 2011;2(6):141-143.

11. Champion JK, Williams M. Small bowel obstruction and internal hernias after laparoscopic roux-en-y gastric bypass. Obes Surg. 2003;13(4):596600 .

12. Schweitzer MA, DeMaria EJ, Broderick TJ, et al. Laparoscopic closure of mesenteric defects after Roux-en-Y gastric bypass. J Laparoendosc Adv Surg Tech A. 2000;10(3):173-175. 